\title{
Characterizing the Distribution of Ppm Gluten in Gluten Free Oatmeal Servings Contaminated with a Wheat Kernel
}

\author{
Ronald D. Fritz ${ }^{1} \&$ Yumin Chen $^{1}$ \\ ${ }^{1}$ PepsiCo R\&D Measurement Sciences, 617 W. Main Street, Barrington, IL 60010, USA \\ Correspondence: Ronald D. Fritz, Measurement Sciences, PepsiCo R\&D, 205 Beelog Rd., Burnsville NC 28714, \\ USA. Tel: 1-828-678-9342. E-mail: ronald.fritz@pepsico.com
}

Received: July 21, 2017

Accepted: August 6, 2017 Online Published: August 25, 2017

doi:10.5539/jfr.v6n5p92

URL: https://doi.org/10.5539/jfr.v6n5p92

\begin{abstract}
Oats are often contaminated with rogue kernels of gluten-containing grains like wheat, barley and rye. When producing gluten free oatmeal, possessing an understanding of the consequences of this possibility is prudent, as labeling requirements specify a maximum amount of gluten in terms of 'parts per million' (ppm) gluten. Variation in contaminant kernels, along with variation due to measurement itself though, can result in a wide range of possible ppm gluten outcomes in contaminated servings. This research pursues characterization of this variability, highlighting contributors to it, doing so by quantifying distributional outcomes of ppm gluten in wheat kernel contaminated servings. This is done via statistical simulation of wheat kernel contaminated servings, done for a collection of wheat types and incorporating various measurement influences. Results indicate substantial variability in ppm gluten per serving for a given wheat type, as well as between them, with this being compounded by the measurement task itself.
\end{abstract}

Keywords: oat, ELISA, gluten, kernel-based gluten contamination, gluten analysis, gluten-free, serving size

\section{Introduction}

Oats are often contaminated with gluten rich grains like wheat and barley (Hernando, Mujico, Mena, Lombardia, \& Mendez, 2008; Koerner et al., 2011; Thompson, 2004; Thompson, Lee, \& Grace, 2010). This 'kernel based' type of contamination complicates attainment and assessment of true gluten free oatmeal (Fritz \& Chen, 2017), as these rogue kernels remain largely intact during processing, being transformed into flakes indiscernible from their oat counterparts. This type of contamination produces a binary type compliance circumstance, since if a contaminant kernel exists in a serving that serving will be high in measured gluten and non-compliant, while if no contaminant kernel exists no gluten will be present (Fritz \& Chen, 2017).

In previous research, spiking of pure oats with contaminate kernels of wheat was conducted (Fritz, Chen \& Contreras, 2017). During this, it was noticed that a surprisingly wide range of ppm gluten outcomes were obtained. This was despite care being taken to contaminate equal serving amounts with wheat kernels of comparable weight and type. These disparate outcomes became the genesis of this research, which seeks to understand and characterize the distribution of ppm gluten outcomes for a wheat kernel contaminated serving of otherwise pure oats.

To accomplish this, kernel attributes which can influence gluten content in wheat were identified, and distributions of these characteristics were obtained/derived from the literature. Measurement influences on the gluten assessment task for oats were also identified and quantified. Where pertinent information could not be found, distributional parameters of certain characteristics were 'guesstimated' and sensitivity analysis performed by perturbing these values in the statistical simulation model. This work resulted in a collection of variables which could be used to simulate servings of contaminated oatmeal, and which could then be collectively used to characterize the distribution of gluten (in ppm) in a defined serving size of gluten free oatmeal. This was done for various wheat kernel varieties and gluten measurement circumstances. These circumstances include distributions for 'actual' ppm outcomes (i.e., absent of measurement influences), ppm outcomes under various measurement scenarios, and done for various wheat classifications. 


\section{Materials and Methods}

\subsection{Methods - Kernel Variability}

It is widely known that gluten resides in the endosperm of wheat, existing in the form of various seed storage proteins (Haraszi, Chassaigne, Maquet, \& Ulberth, 2011; Huebner, 1970; Rallabhandi, Sharma, Pereira, \& Williams, 2015; Shewry, 2009). Based on this, four key variables are believed to directly influence the gluten content of a wheat kernel. They are:

1. kernel weight

2. $\%$ of kernel weight due to moisture

3. $\%$ of dry kernel weight that is protein

4. \% of this kernel protein which is gluten (i.e., gliadins and glutenins) (Mejías et al., 2014; Shewry, 2009).

Found in published literature, estimates of distribution parameters for the above, for both hard and soft wheat classifications, are shown in table 1 . Note that the stdev of '\% protein that's gluten' was unable to be found in the literature and has been 'guesstimated' here. Sensitivity analysis around this 'guesstimate' has been performed and will be reported in the results and discussion section of this paper. Also note that these variables are assumed to be normally distributed. Evidence of this exists for '\% protein' (Levi, 1950), and this is believed a reasonable assumption for 'weight', 'moisture' and '\% protein that's gluten' as well.

Table 1. Approximate distributional parameters for individual wheat kernels based on hardness classification for four key variables affecting individual kernel gluten content

\begin{tabular}{|c|c|c|c|c|c|c|c|c|}
\cline { 2 - 8 } \multicolumn{1}{c|}{} & \multicolumn{2}{c|}{$\begin{array}{c}\text { Kernel } \\
\text { Weight (g) }\end{array}$} & \multicolumn{2}{c|}{$\begin{array}{c}\text { Kernel } \\
\text { Moisture (\%) }\end{array}$} & $\begin{array}{r}\text { Kernel } \\
\text { \% Protein } \\
\text { (Gliadins + Glutenins) }\end{array}$ & \multicolumn{2}{|c|}{$\begin{array}{c}\text { \% Protein } \\
\text { as Gluten }\end{array}$} \\
\hline $\begin{array}{c}\text { Assumed } \\
\text { Distribution } \\
\text { Type }\end{array}$ & \multicolumn{2}{|c|}{ Normal } & \multicolumn{2}{|c|}{ Normal } & \multicolumn{2}{c|}{$\begin{array}{c}\text { Normal } \\
\text { (Levi, 1950) }\end{array}$} & \multicolumn{2}{c|}{ Normal } \\
\cline { 2 - 9 } & $\sim$ Avg. & $\sim$ Stdev & $\sim$ Avg. & $\sim$ Stdev & $\sim$ Avg. & $\sim$ Stdev & $\sim$ Avg. & $\sim$ Stdev \\
\hline $\begin{array}{c}\text { Soft } \\
\text { Wheat }\end{array}$ & 0.041 & 0.006 & $12.7 \%$ & $2.4 \%$ & $9.6 \%$ & $2.1 \%$ & $76.7 \%$ & $4.0 \%$ \\
\hline $\begin{array}{c}\text { Hard } \\
\text { Wheat }\end{array}$ & 0.035 & 0.010 & $11.1 \%$ & $1.8 \%$ & $13.3 \%$ & $2.4 \%$ & $80.3 \%$ & $4.0 \%$ \\
\hline $\begin{array}{c}\text { Data } \\
\text { Source }\end{array}$ & $($ Liu, 2008) & \multicolumn{2}{|c|}{$($ Liu, 2008) } & (Delwiche, 1995) & $\begin{array}{c}\text { (Seilmeier, } \\
1991)\end{array}$ & $\begin{array}{c}\text { Guess- } \\
\text { timate }\end{array}$ \\
\hline
\end{tabular}

These four variables are also assumed to be independent of each other (i.e., not correlated.) This appears to be the case regarding protein content relative to dry kernel weight (Delwiche, 1995), where no relationship was apparent for hard white wheat in that research. Other relationships between these variables, or lack of them, are not well defined in the literature but are assumed herein not to exist.

\subsection{Methods - Measurement Variability}

Three measurement variables were considered in characterizing the ppm gluten in a wheat contaminated serving of otherwise gluten-free oatmeal. This was to determine gluten content 'as assessed' vs. an estimate of 'actual true gluten' exclusive of measurement itself. These measurement variables are:

5. \% of gluten protein which is gliadin (this is technically a kernel attribute but is included here due to its significant impact on gluten assessment since test kits measure gliadin only)

6. \% analytical recovery of gliadin

7. Effects of grinding non-homogeneity (of a wheat kernel in oats).

As mentioned, the variable ' $\%$ of gluten protein which is gliadin' is included in the measurement category here since gluten test kits rely on measurement of gliadins only and estimate a doubling of this for potential gluten containing glutenin proteins also present in the kernel. Glutenins can contain significant amounts of gluten as well (Huebner, 1970; Selmeier, Belitz \& Wieser, 1991; Weiser \& Koehler, 2009; Haraszi et al., 2011; Zilic, Barc, Pesic, Dodig \& Ignjatovic-Micic, 2011; Diaz-Amigo \& Popping, 2013; Khan et al., 2013).

' $\%$ analytical recovery' has been included since no validation of this for oats is believed to have been performed, as there's no record of this published by Biopharm at this time. It is also possible that this may vary somewhat 
'test to test' as well.

The 'effect of grinding non-homogeneity' has been included since it has been found that this inflates gluten ppm test outcome variability, producing a lognormal distribution of gluten test results (Fritz et al., 2017).

Estimates of distribution parameters for the above three variables, along with their data sources, are shown in table 2. Note that the stdev of '\% gluten protein that's gliadin' was unable to be found in the literature and has been 'guesstimated' here. This is the case with the stdev of 'analytical recovery' of gliadin as well. Sensitivity analysis around both of these 'guesstimates' has been performed and will be reported in the results and discussion section of this paper.

Also note that '\% Gluten Protein that's Gliadin' and 'Analytical Recovery (\%)' have been assumed to be normally distributed.

Table 2. Approximate distributional parameters for measurement related variables that affect gluten content assessments of gluten-free oatmeal contaminated with a single wheat kernel

\begin{tabular}{|c|c|c|c|c|c|c|}
\cline { 2 - 7 } \multicolumn{1}{c|}{} & \multicolumn{2}{c|}{$\begin{array}{c}\text { \% Gluten Protein } \\
\text { that's Gliadin }\end{array}$} & \multicolumn{2}{|c|}{$\begin{array}{c}\text { Analytical } \\
\text { Recovery (\%) } \\
\text { (Gliadin) }\end{array}$} & \multicolumn{2}{c|}{$\begin{array}{c}\text { Grinding Non- } \\
\text { Homogeneity }\end{array}$} \\
\hline $\begin{array}{c}\text { Assumed } \\
\text { Distribution } \\
\text { Type }\end{array}$ & $\sim$ Normal & \multicolumn{2}{|c|}{ Normal } & \multicolumn{2}{|c|}{ Log-Normal } \\
\cline { 2 - 7 } & $\sim$ Avg. & $\sim$ Stdev & $\sim$ Avg. & $\sim$ Stdev & $\begin{array}{c}\sim \text { Avg. of } \\
\text { Stdev of In } \\
\text { values }\end{array}$ & $\begin{array}{c}\sim \text { Stdev of } \\
\text { Stdev of Ln } \\
\text { Values }\end{array}$ \\
\hline Wheat & $50.0 \%$ & $7.0 \%$ & $80.0 \%$ & $8.5 \%$ & 0.510 & 0.082 \\
\hline $\begin{array}{c}\text { Data } \\
\text { Source }\end{array}$ & $\begin{array}{c}\text { (Huebner, } \\
1970)\end{array}$ & $\begin{array}{c}\text { Guess- } \\
\text { timate }\end{array}$ & $\begin{array}{c}\text { (BioPharm, } \\
2012)\end{array}$ & $\begin{array}{c}\text { Guess- } \\
\text { timate }\end{array}$ & $($ Fritz, 2017) \\
\hline
\end{tabular}

\subsection{Methods - Simulation}

These seven variables, four being wheat characteristics (i.e., characterized in Table 1) and three measurement variables (i.e., characterized in Table 2), have been used to simulate a serving of gluten-free oatmeal (of $40 \mathrm{~g}$ size) which is contaminated by a single wheat kernel. A simulated serving then, is $40 \mathrm{~g}$ of pure oats, contaminated by a randomly selected wheat kernel of a certain weight, moisture, protein content, and ' $\%$ of that protein that's gluten' (i.e., gliadin plus glutenin). These values are based on random selection from the distributions for these variables defined in table 1 . These kernel characteristics are considered independent of each other, so a kernel of a certain weight is randomly chosen from the 'weight' distribution, then a moisture content is randomly assigned to it from the 'moisture' distribution, then '\% protein' and '\% protein that's gluten' values are assigned, again with these coming from their respective distributions of possibilities. So, for a 'true' ppm gluten assessment (exclusive of any measurement error), the following defines a single simulated wheat kernel's contribution in ppm gluten in a $40 \mathrm{~g}$ serving of pure oats:

PPM gluten $_{\text {true }}=\left[(\right.$ weight in $\mu \mathrm{g}) \times\left(\left(100-{ }^{\circ} \%\right.\right.$ moisture' $\left.) / 100\right) \times\left({ }^{\circ} \%\right.$ Protein'/100) $\times\left({ }^{\circ} \%\right.$ Protein that's Gluten'/100)]/40g

To this, measurement variables are then assigned. So, the ' $\%$ gluten that's gliadin' is randomly chosen from the distribution defined for it, along with an analytical recovery value from its distribution. Both of these are assumed normally distributed as well. This gives us the following for a 'pre-grind' ppm gluten for a serving:

PPM gluten ${ }_{\text {pre-grind }}=\left(\right.$ PPM gluten $\left.{ }_{\text {true }}\right) \times 2$ x ((‘\% Gluten that’s Gliadin’ $\left.) / 100\right) \times($ \% Analytical Recovery'/100)

By 'pre-grind' is meant prior to incorporating the variability due to the inability to achieve an homogenous grind of gluten in a serving of oats (Fritz et al., 2017). Also, the ' 2 ' ' in this equation is the recommended test kit multiplier which presumes a Gliadin/Glutenin ratio of 1:1, and therefore a doubling of the gliadin to obtain an estimate of total gluten.

For the final 'post-grind' ppm value for a serving, the 'PPM gluten pre-grind ' outcome for a kernel in $40 \mathrm{~g}$ of oats is used as the gluten ppm average of a log-normally distributed collection of $0.25 \mathrm{~g}$ test results in a $40 \mathrm{~g}$ serving 
(Fritz, 2017.) The natural log of this value is considered the average of a normally distributed random variable whose stdev is then randomly selected from a normal distribution whose parameters are shown in Table 2, namely 0.51 average and 0.082 stdev. These values come from studies conducted previously (Fritz et al., 2017). So the final ppm gluten for a serving, denoted as 'PPM gluten post-grind', is then the anti-log of this $\log$ transformed value, defined by:

$$
\text { PPM gluten } \text { post-grind }=\mathrm{e}^{\ln (\text { PPM gluten post-grind transformed })}
$$

So the above is done for 25,000 simulated wheat kernels, each in $40 \mathrm{~g}$ servings of otherwise pure oats. The resultant 25,000 simulated ppm gluten values are then used to characterize the distribution of ppm gluten contamination of a $40 \mathrm{~g}$ serving of pure oats contaminated with a kernel of wheat.

\subsection{Data Analysis}

Simulation of servings was performed in Excel, Microsoft Office 2013, using sampling from the distributions of key characteristics of wheat kernels defined and doing the same for the measurement variables.

\section{Results and Discussion}

\subsection{PPM Distribution of Gluten in a Serving of Pure Oats Contaminated with a Single Hard Wheat Kernel under Various Measurement Circumstances}

Based on simulated servings of pure oats contaminated with a single hard wheat kernel, Table 3 shows outcomes obtained for ppm gluten per serving. The first row shows the estimated 'actual', i.e., 'true' ppm gluten in a $40 \mathrm{~g}$ contaminated serving, without the influence that measurement brings into the equation. Here we obtain a normal-like distribution with average of $83 \mathrm{ppm}$ and a stdev of 28 for hard wheat with parameters as shown. A $95 \%$ confidence interval about the average would cover roughly 30 to $140 \mathrm{ppm}$. This illustrates the wide variability potential due solely to 'kernel to kernel' differences within the classification of 'hard' wheat (based on the presumed distributional parameters used for the four kernel characteristics included in the simulation). This shows why in previous research we obtained surprising variability in ppm gluten in servings of oats spiked with the same variety and weight wheat kernels. Kernel to kernel variability plays a large role in observed variability of ppm gluten per contaminated serving. NOTE: Ten replicate simulations of the same 'settings' were conducted for all kernel and measurement circumstances in this study. This was to evaluate the stability or lack thereof of the resultant simulation outcomes. Outcomes were found repeatable with $<+/-1 \mathrm{ppm}$ differences in averages obtained and $<+/-6$ ppm differences in standard deviations obtained.

Table 3. Simulated outcomes of ppm gluten in gluten-free oatmeal servings (40g) contaminated with a single hard wheat kernel under various measurement circumstances. $(n=25,000$ simulated servings.)

\begin{tabular}{|c|c|c|c|c|c|c|c|c|c|c|c|c|c|c|c|c|c|c|c|}
\hline \multirow{3}{*}{$\begin{array}{l}\text { Simul- } \\
\text { ation }\end{array}$} & \multirow{3}{*}{$\begin{array}{l}\text { Theor- } \\
\text { etical } \\
\text { PPM } \\
\text { Calc. } \\
(12 \% \\
\text { Moisture) }\end{array}$} & \multicolumn{8}{|c|}{ Kernel Variable Settings } & \multicolumn{6}{|c|}{ Measurement Variable Settings } & \multirow{3}{*}{$\begin{array}{l}\text { Dist. } \\
\text { Shape }\end{array}$} & \multirow{3}{*}{$\begin{array}{c}\text { Avg. } \\
\text { PPM } \\
\text { Gluten }\end{array}$} & \multirow{3}{*}{\begin{tabular}{|c|} 
Stdev \\
of \\
PPM \\
Gluten
\end{tabular}} & \multirow{3}{*}{ Plot } \\
\hline & & \multicolumn{2}{|c|}{$\begin{array}{c}\text { Kernel } \\
\text { Weight (g) }\end{array}$} & \multicolumn{2}{|c|}{$\begin{array}{c}\text { Kernel } \\
\text { Moisture } \\
(\%)\end{array}$} & \multicolumn{2}{|c|}{$\begin{array}{c}\text { Kernel } \\
\text { \% Protein } \\
\text { (Gliadins + Glutenins) }\end{array}$} & \multicolumn{2}{|c|}{$\begin{array}{l}\text { \% Protein } \\
\text { as Gluten }\end{array}$} & \multicolumn{2}{|c|}{$\begin{array}{l}\text { \% Gluten } \\
\text { that's } \\
\text { Gliadin }\end{array}$} & \multicolumn{2}{|c|}{$\begin{array}{l}\text { Analytical } \\
\text { Recovery } \\
\text { (\% Gliadin) }\end{array}$} & \multicolumn{2}{|c|}{$\begin{array}{l}\text { Grinding Non- } \\
\text { Homogeneity }\end{array}$} & & & & \\
\hline & & Avg. & Stdev & Avg. & Stdev & Avg. & Stdev & Avg. & Stdev & Avg. & Stdev & Avg. & Stdev & $\begin{array}{c}\text { Avg. of } \\
\text { Stdev of } \\
\text { 'In' values }\end{array}$ & $\begin{array}{c}\text { Stdev of } \\
\text { Stdev of } \\
\text { 'In' Values }\end{array}$ & & & & \\
\hline $\begin{array}{l}\text { Hard Wheat, } \\
\text { Actual, } \\
\text { 40g Serving }\end{array}$ & \multirow{6}{*}{82} & \multirow{6}{*}{0.035} & \multirow{6}{*}{0.01} & \multirow{6}{*}{$11.1 \%$} & \multirow{6}{*}{$1.8 \%$} & \multirow{6}{*}{$13.3 \%$} & \multirow{6}{*}{$2.4 \%$} & \multirow{6}{*}{$80.3 \%$} & \multirow{6}{*}{$4 \% *$} & \multicolumn{2}{|c|}{ NA } & \multicolumn{2}{|c|}{ NA } & \multicolumn{2}{|c|}{ NA } & $\begin{array}{c}\text { Normal- } \\
\text { Like, Slight } \\
\text { Right Skew }\end{array}$ & 83 & 28 & \\
\hline \multirow{5}{*}{$\begin{array}{l}\text { Hard Wheat, } \\
\text { As } \\
\text { Measured, } \\
\text { 40g Serving }\end{array}$} & & & & & & & & & & $33 \%$ & \multirow{5}{*}{$7 \% * *$} & $80 \%$ & \multirow{5}{*}{$\begin{array}{c}8.5 \% \\
* * *\end{array}$} & \multirow{5}{*}{$\begin{array}{l}0.51 \\
* * * *\end{array}$} & \multirow{5}{*}{0.082} & $\begin{array}{l}\text { Log- } \\
\text { Normal } \\
\text { Like }\end{array}$ & 50 & 37 & \\
\hline & & & & & & & & & & $50 \%$ & & $80 \%$ & & & & $\begin{array}{l}\text { Log- } \\
\text { Normal } \\
\text { Like }\end{array}$ & 76 & 54 & \\
\hline & & & & & & & & & & $76 \%$ & & $80 \%$ & & & & $\begin{array}{l}\text { Log- } \\
\text { Normal } \\
\text { Like }\end{array}$ & 116 & 83 & \\
\hline & & & & & & & & & & $50 \%$ & & $70 \%$ & & & & $\begin{array}{l}\text { Log- } \\
\text { Normal } \\
\text { Like }\end{array}$ & 67 & 48 & \\
\hline & & & & & & & & & & $50 \%$ & & $90 \%$ & & & & $\begin{array}{l}\text { Log- } \\
\text { Normal } \\
\text { Like }\end{array}$ & 86 & 61 & \\
\hline
\end{tabular}

* - Varying this from $1 \%$ to $8 \%$ (and for an 'actual' result not affected by measurement) resulted in a modest increase in ppm gluten stdev from $\sim 28 \%$ to $~ 29 \%$

** - Varying this from $1 \%$ to $12 \%$ (with $50 \%$ assumed gliadin) resulted in an increase in ppm gluten stdev from $53 \%$ to $~ 58 \%$

*** - Varying this from $1 \%$ to $8.5 \%$ (with $50 \%$ assumed gliadin) resulted in a slight increase in ppm gluten stdev from $~ 53.4 \%$ to $~ 54 \%$

**** - Varying this from 0.4 to 0.6 (with $50 \%$ assumed gliadin \& $80 \%$ analytical recovery) resulted in ppm gluten averages from 72 to 84 with stdevs from 44 to 66 respectively. 
Also shown in Table 3, are outcomes including measurement variability for the same hard wheat kernel category. Here we see that sample grind non-homogeneity alters the distribution of ppm gluten/serving from a normal-like distribution to a log-normal-like one (Fritz et al, 2017.) And, that this is responsible for further inflating the variability of possible outcomes (relative to the true variability due just to 'kernel to kernel' variability.) Solutions to this grinding non-homogeneity issue could substantially improve ppm gluten outcomes 'as measured', providing more accuracy and precision in assessment of serving gluten content.

Along with this, the other two measurement variables play into inflated variability of ppm gluten/serving outcomes as well. For instance, the '\% gluten that's gliadin' plays a big role as test kits measure only gliadin and assume a 1:1 ratio of gliadin to glutenin (Huebner, 1970). Doing a survey of research regarding gliadin/glutenin ratios though, shows this ratio can vary substantially (Huebner, 1970; Selmeier et al., 1991; Weiser \& Koehler, 2009; Haraszi et al., 2011; Zilic et al., 2011; Diaz-Amigo \& Popping, 2013; Khan et al., 2013), as illustrated in Table 4. Varying gliadin as a percent of total gluten, from $33 \%$ to $70 \%$, produces average ' $\mathrm{ppm} / \mathrm{serving}$ gluten' from $50 \mathrm{ppm}$ to $110 \mathrm{ppm}$, and with stdevs from $37 \mathrm{ppm}$ to $83 \mathrm{ppm}$ respectively, as shown in Table 3 . This illustrates that improved test kit design, which better accounts for the glutenin portion of overall gluten, would provide improved accuracy and precision in the assessment of gluten content caused by wheat kernel contamination in oats.

Table 4. \% Gluten due to Gliadin and Glutenin cited in various research studies

\begin{tabular}{|c|c|c|}
\hline \multirow{2}{*}{ Study } & \multicolumn{2}{|c|}{ \% of Total Gluten } \\
\cline { 2 - 3 } & Gliadin & Glutenin \\
\hline Huebner, 1970 & $50 \%$ & $50 \%$ \\
\hline Selmeier, 1991 & $38 \%$ & $62 \%$ \\
\hline Weiser, 2009 & $60 \%-76 \%$ & $24 \%-40 \%$ \\
\hline Haraszi, 2011 & $65 \%$ & $35 \%$ \\
\hline Zilic, 2011 & $33 \%-50 \%$ & $50 \%-67 \%$ \\
\hline Diaz-Amigo, 2013 & $57 \%-62 \%$ & $38 \%-43 \%$ \\
\hline Khan, 2013 & $62 \%-69 \%$ & $31 \%-38 \%$ \\
\hline
\end{tabular}

Finally, analytical recovery of gluten in oats is not believed to have been validated as of yet. (At least there's no record of this published by Biopharm at this time.) The 80\% figure often cited is for corn (R-Biopharm, 2012). To account for recovery of gluten in oats possibly being under or over stated due to this, we performed sensitivity analysis by perturbing analytical recovery from $70 \%$ to $90 \%$. We found that this range affects average ppm gluten/serving by about $20 \mathrm{ppm}$, and increased the stdev of ppm gluten/serving from 48 to $61 \mathrm{ppm}$ as shown in the bottom two rows of Table 3 .

Note also that in table 3, there are comments regarding sensitivity analysis to the 'guesstimates' made for the stdevs of:

- $\%$ Protein that's Gluten

- $\%$ Gluten that's Gliadin'

- 'Analytical Recovery.'

In all cases, altering these as noted produced only modest influences on resultant ppm gluten/serving results.

In summary, kernel to kernel variability can produce widely varying outcomes in terms of ppm gluten/serving when a wheat kernel exists in a serving. Also, measurement further compounds this by inflating variability due to varying gliadin/glutenin ratios, non-homogenous grinding and potentially a test method not yet validated for oats in terms of analytical recovery of gluten.

\subsection{Comparing PPM Distributions of Gluten/Serving in Oats Contaminated with a Wheat Kernel, Using Different Wheat Types}

There are substantial differences in kernel size, moisture, protein, etc. between different varieties of wheat (http://www.uswheat.org/reports). Table 5 shows approximate values of weight, moisture content and protein for some major sub-classifications of wheat. Table 5 also shows simulated outcomes of the distribution of ppm gluten/serving as measured (employing stdevs from the larger categories of hard and soft wheat used earlier, and also with assumptions of 50/50 gliadin to glutenin ratio and $80 \%$ recovery). The differences in average contamination obtained between wheat types, varies from a low of $50 \mathrm{ppm}$ up to $110 \mathrm{ppm}$. This illustrates the differences that exist in contamination potency between differing types of wheat. 
Table 5. Simulated outcomes of ppm gluten in gluten-free oatmeal servings (40g) contaminated with a single wheat kernel for both Hard and Soft Wheat. ( $n=25,000$ simulated servings.)

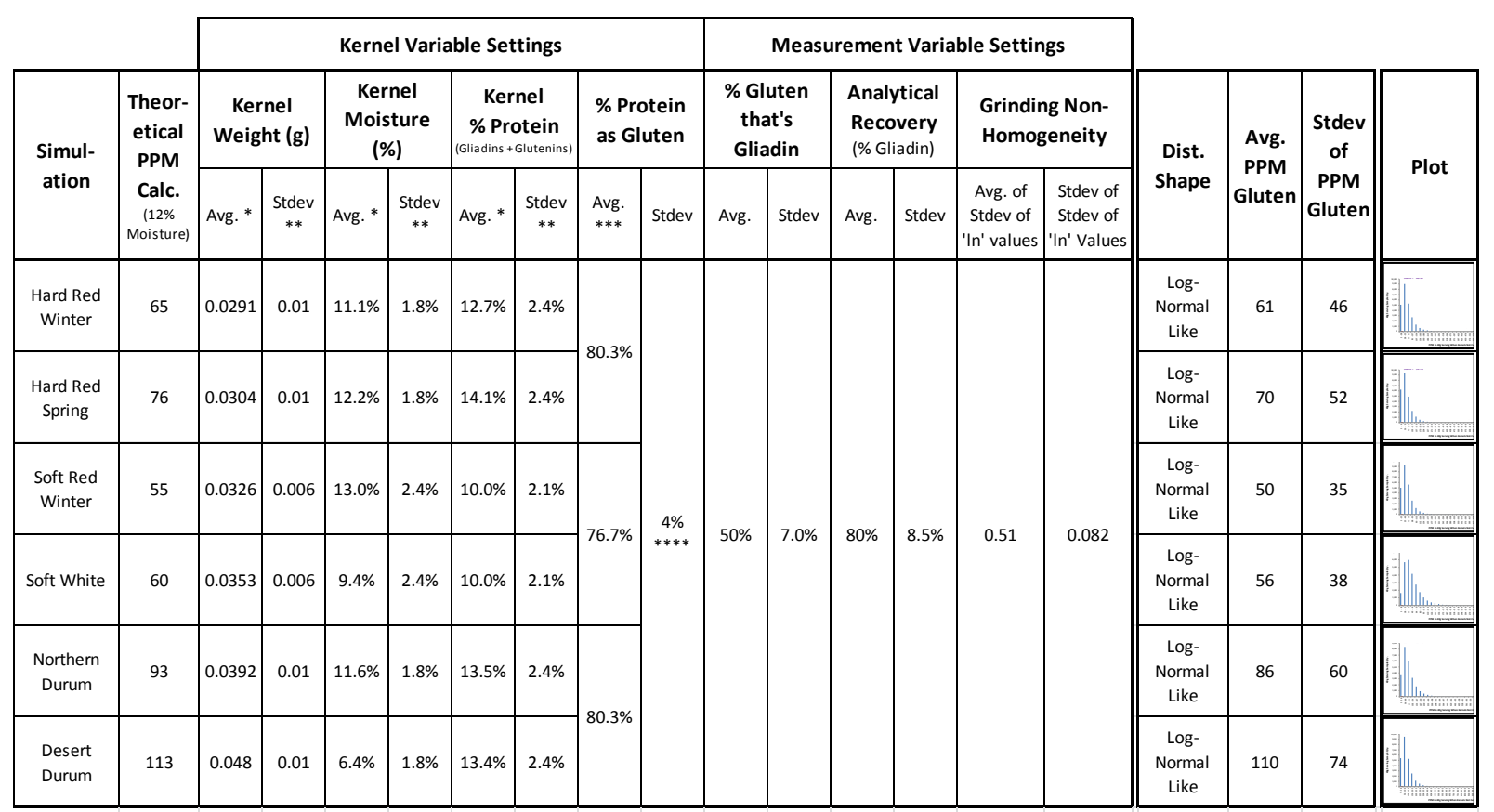

* - Five year average values reported in 2015 Crop Quality Report by US Wheat Associates, http://www.uswheat.org/cropQuality

** - Liu (2008)

*** - Seilmeier (1991)

**** - Guesstimate (variation in this shown to be a minimal influencer on ppm gluten/serving)

\section{Conclusion}

Oats are easily contaminated with gluten rich kernels of wheat. As shown here, the extent of actual contamination per serving in terms of ppm gluten can vary widely when this occurs. This is due to kernel to kernel variability within varieties, as well as between them. The measurement of gluten itself compounds this variability as well. Primary components of measurement influence are the use of gliadin as a 50\% marker for glutenins when gliadin/glutenin ratios can actually vary substantially, the inability to homogenously grind a wheat kernel within a serving of otherwise gluten-free oats and finally the potential for variability in analytical recovery sample to sample. All of this adds up to produce a substantial range of possible outcomes when a gluten kernel exists in a serving of otherwise gluten-free oats.

\section{Acknowledgements}

The authors declare that they have no competing interests. All the authors are salaried employees of PepsiCo Inc. or Quaker Foods and Snacks (QFS), a subsidiary of PepsiCo Inc., which funded this research. QFS has a commercial interest in gluten-free foods. The views expressed in this manuscript are those of the authors and do not necessarily reflect the position or policy of PepsiCo Inc.

\section{References}

Delwiche, Stephen, R. (1995). Single Wheat Kernel Analysis by Near-Infrared Transmittance: Protein Content. Cereal Chemistry, 72(1), 11-16.

Diaz-Amigo, C., \& Popping, B., (2013). Accuracy of ELISA Detection Methods for Gluten and Reference Materials: A Realistic Assessment. J. Agric. Food Chem., 61, 5681-5688. https://doi.org/10.1021/jf3046736

Fritz, R. D., \& Chen, Y. (2017). Kernel-based gluten contamination of gluten-free oatmeal complicates gluten assessment as it causes binary-like test outcomes. International Journal of Food Science \& Technology, 52(2), 359-365. https://doi.org/10.1111/ijfs.13288

Fritz, R. D., Chen, Y., \& Contreras, V. (2017). Gluten-containing grains skew gluten assessment in oats due to sample grind non-homogeneity. Food Chemistry, 216, 170-175.

https://doi.org/10.1016/j.foodchem.2016.08.031

Haraszi, R., Chassaigne, H., Maquet, A., \& Ulberth, F. (2011). Analytical Methods for Detection of Gluten in 
Food - Method Developments in Support of Food Labeling Legislation. Journal of AOAC International, 94(4), 1006-1025

Hernando, A., Mujico, J. R., Mena, M. C., Lombardia, M., \& Mendez, E. (2008). Measurement of wheat gluten and barley hordeins in contaminated oats from Europe, the United States and Canada by Sandwich R5 ELISA. Eur J Gastroenterol Hepatol, 20(6), 545-554. https://doi.org/10.1097/MEG.0b013e3282f46597

Huebner, F. R. (1970). Comparative Studies on Glutenins From Different Classes of Wheat. Agricultural and Food Chemistry, 18, 256-259. https://doi.org/10.1021/jf60168a006

Huebner, F. R., Kaczkowski, J., \& Bietz, J. A. (1990). Quantitative Variation of Wheat Proteins from Grain at Different Stages of Maturity and from Different Spike Locations. Cereal Chemistry, 67(5), 464-470.

Khan, S., Ghanghro, A.B., Memon, A. N., Tahir, I., Shah, A. M., Sahito, M. A., Talpur, F. N., \& Qureshi, S. (2013). Quantitative Analysis of Wheat Proteins in Different Varieties Grown In Sindh, Pakistan. Intl J Agri Crop Sci., 5(16), 1836-1839.

Koerner, T. B., Cleroux, C., Poirier, C., Cantin, I., Alimkulov, A., \& Elamparo, H. (2011). Gluten contamination in the Canadian commercial oat supply. Food Addit Contam Part A Chem Anal Control Expo Risk Assess, 28(6), 705-710. https://doi.org/10.1080/19440049.2011.579626

Levi, I., \& Anderson, J. A. (1950). Variations in Protein Contents of Plants, Heads, Spikelets, and Individual Kernels of Wheat. Canadian Journal of Research, F. 28, 71-81. https://doi.org/10.1139/cjr50f-006

Liu, K. (2008). Measurement of Wheat Hardness by Seed Scarifier and Barley Pearler and Comparison with Single-Kernel Characterization System. Cereal Chemistry, 85(2), 165-173. https://doi.org/10.1094/CCHEM-85-2-0165

Mejias, J., Lu, X., Osorio, C., Ullman, J. L., von Wettstein, D., \& Rustgi, S. (2014). Analysis of Wheat Prolamins, the Causative Agents of Celiac Sprue, Using Reversed Phase High Performance Liquid Chromatography (RP-HPLC) and Matrix-Assisted Laser Desorption Ionization Time of Flight Mass Spectrometry (MALDI-TOF-MS). Nutrients, 6, 1578-1597. https://doi.org/10.3390/nu6041578

R-Biopharm, AG. (2012), Ridascreen Gliadin Art. No. R7001 Validation Report.

Rallabhandi, P., Sharma, G. M., Pereira, M., \& Williams, K. M. (2015). Immunological Characterization of the Gluten Fractions and Their Hydrolysates from Wheat, Rye and Barley. J. Agric. Food Chem., 63, 1825-1832. https://doi.org/10.1021/jf505716p

Seilmeier W, Belitz, H-D, \& Wieser, H. (1991). Separation and quantitative determination of high-molecular-weight subunits of glutenin from different wheat varieties and genetic variants of the variety Sicco. Zeitschrift für Lebensmittel-Untersuchung und Forschung, 192, 124-129. https://doi.org/10.1007/BF01202625

Shewry, P. R. (2009). Wheat. Journal of Experimental Botany, 60, 1537-1553. https://doi.org/10.1093/jxb/erp058

Thompson, T. (2004). Gluten Contamination of Commercial Oat Products in the United States. New England Journal of Medicine, 351(19), 2021-2022. https://doi.org/10.1056/NEJM200411043511924

Thompson, T., Lee, A. R., \& Grace, T. (2010). Gluten contamination of grains, seeds, and flours in the United States: a pilot study. J Am Diet Assoc, 110(6), 937-940. https://doi.org/10.1016/j.jada.2010.03.014

Weiser, H., Koehler, P. 2009). Is the calculation of the gluten content by multiplying the prolamin content by a factor of 2 valid?, Euro. Food Res. \& Tech., 229(1), 9-13. https://doi.org/10.1007/s00217-009-1020-5

Zilic, S., Barac, M., Pesic, M., Dodig, D., \& Ignjatovic-Micic, D. (2011). Characterization of Proteins from Grain of Different Bread and Durum Wheat Genotypes. Int. J. Mol. Sci., 12, 5878-5894. https://doi.org/10.3390/ijms12095878

\section{Copyrights}

Copyright for this article is retained by the author(s), with first publication rights granted to the journal.

This is an open-access article distributed under the terms and conditions of the Creative Commons Attribution license (http://creativecommons.org/licenses/by/4.0/). 